\title{
Ground Based Kinematic GNSS Observation Results Affected by Space Weather Fluctuations in 2015
}

\author{
Janis BALODIS, Inese VARNA, Diana HARITONOVA, \\ Madara NORMAND, Gunars SILABRIEDIS \\ Institute of Geodesy and Geoinformatics, \\ University of Latvia, Raina blv.19, Riga, LV-1586, Latvia \\ janis.balodis@lu.lv, inesej@inbox.lv, diana.haritonova@lu.lv, \\ madaracaunite@yahoo.com, gunars.silabriediselu.lv
}

\begin{abstract}
The five-minute resolution GNSS observation results were computed in kinematic mode by scientific post-processing software for the 30 continuously operating GNSS reference stations covering the territory of Latvia. The cases of disturbed coordinate values were searched among computed results in three selected periods: the week of St.Patrick's Day storm in March 2015, June and September 2015. The events of computed coordinate disturbances were found. They are noticed as features of the ionospheric scintillation which discovered as the failed coordinate appearance. The statistics of the disturbance occurrences was analyzed in relation to geomagnetic storms registered by international services. Events of both disturbances and domes of affected GNSS reference stations were listed and the comparison with a schedule of strongest geomagnetic storms was performed. Plots of coordinate disturbances at some GNSS continuously operating reference stations were designed. The subset of most affected GNSS reference stations was discovered.

It was concluded that the five-minute resolution GNSS observation results computed in kinematic mode for the GNSS ground based continuously operating reference stations are representing a reasonable contribution for recognition of space weather anomalies as a reason for GNSS related navigation.
\end{abstract}

Keywords: disturbed GNSS, ionosphere fluctuations, geomagnetic storms

\section{Introduction}

In various research papers the irregularities of ionosphere total electron content (TEC) are discussed which sometimes strongly affect the results of GNSS (Global Navigation Satellite Systems) positioning (Astafyeva et al., 2015; Goodwin et al., 2015; Liu et al., 2015). The obtained results of this paper were achieved at the Institute of Geodesy and Geoinformatics (GGI) many months after the GNSS observations were collected and when the corresponding TEC corrections were available they could be taken into account. However, "in general, the sunspot takes place ahead of TEC change by about two days" (Jinyun et al., 2015). In order to check this reality an ionospheric scintillation events were fixed as the result of possible ionosphere disturbed coordinate appearance in five-minute resolution GNSS observation results computed using Precise Point 
Positioning (PPP) technique in kinematic mode. The raw observation data were collected from 30 GNSS ground based continuously operating reference station (CORS) observation sites in Latvia. The internationally applied global data corrections (GNSS orbit and clock corrections, Earth rotation, ionosphere and troposphere corrections) and computation methods of Bernese 5.2 software are used (Dach et al., 2015). The Bernese GNSS Software V5.2 is a scientific, high-precision, GPS/GLONASS (GNSS) data postprocessing software package developed at the Astronomical Institute of the University of Bern. It consists of multiple sub-programs with wide possibilities. Mainly it is used for estimation of static daily GNSS coordinate solutions, but it also allows the estimation of kinematic GNSS receiver coordinates in the zero-difference and precise point positioning mode. In the GNSS observable analysis, kinematic positions allows to track sub-daily movement of a static station, for example, changes in antenna position due to an earthquake. The Bernese GNSS Software V5.2 is used in most of European countries for the postprocessing of most precise GNSS observations. However, several additional service programmes has been developed in GGI for the analysis of current huge amount of computed results.
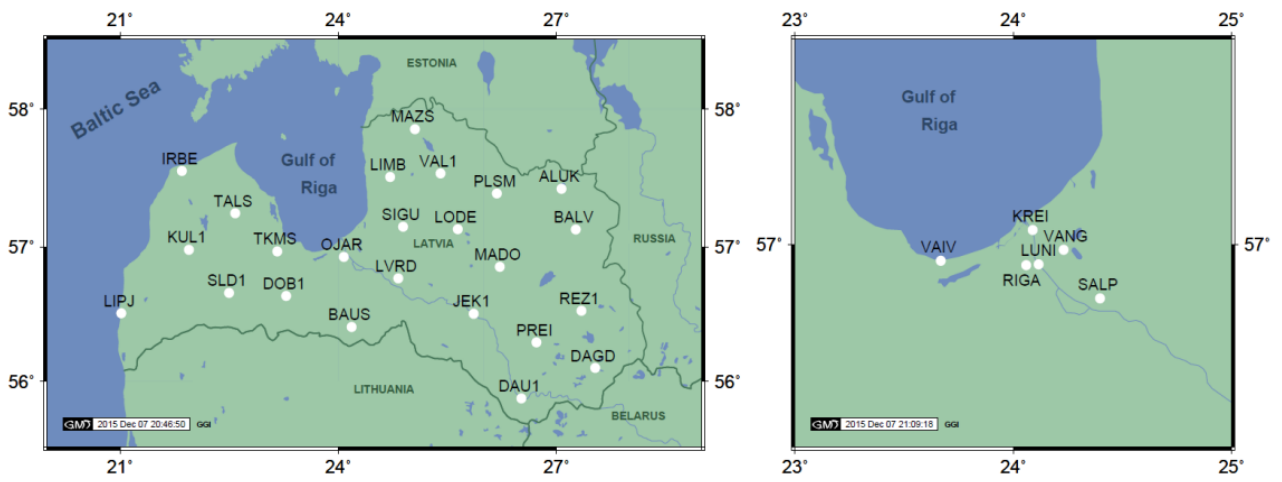

Fig.1. CORS station location with DOMES names in Latvia (left) and Riga (right)

9 IGS/EPN reference station observations are used to compute the coordinates of Latvian CORS: LatPos (24 stations) and $\operatorname{EUPOS}^{\circledR}$-Riga (5 stations) (Figure 1). Registered DOMES names of 9 IGS/EPN reference stations are: JOEN (Finland), MAR6 and ONSA (Sweden), PULK (Russia), RIGA (Latvia), VLNS (Lithuania), GLSV (Ukraine), BOR1 and LAMA (Poland). Three different periods were selected for year 2015 - one week of March, full month periods of June and September, correspondingly. 288 solutions were performed for each day of selected calendar periods for time span $0^{\mathrm{h}}$ till $24^{\mathrm{h}}$ for each day for all of 30 Latvian CORS stations. The discovered scintillation results were considered in relation to 50 yearly strongest geomagnetic storms (WEB (a)).

\section{Strongest geomagnetic storm of 17-18 March 2015}

The geomagnetic storm of 17-18 March 2015 (the St. Patrick's Day storm) was up to now the strongest in the 24th solar cycle (Astafyeva et al., 2015). The storm caused 
complex radio navigation disturbance effects around the globe. The high-resolution multipoint observations from the spacecraft (Domboos et al., 2010) enabled to perform the Swarm in situ plasma electron density structure observations of $F$ region polar cap patches created by cusp precipitation (Goodwin et al., 2015). The global studies were performed by international team (Cherniak et al., 2015) where 2700 measurements were used from GNSS receivers onboard five low earth orbit (LEO) satellites - Swarm A, B and C, GRACE and TerraSAR-X - that had close orbit altitudes of $\sim 500 \mathrm{~km}$, and from the ground-based GNSS stations as well (Cherniak et al., 2015). The strong ionospheric irregularities were observed in the topside ionosphere during the storm's main phase that were associated with storm-enhanced density (SED) formation at midlatitudes and further evolution of the SED plume to the polar tongue of ionization (TOI). The polar patches and TOI structures in the topside ionosphere were predominantly observed in the Southern Hemisphere, which had much higher plasma densities than the Northern Hemisphere (Cherniak et al., 2015).

Strong GNSS disturbances, measured by the rate-of-TEC index (ROTI), were observed at all latitudes in Norway on March 17th and early on March 18th. Late on the March 18th, strong disturbances were only observed in northern parts of Norway (Jacobsen and Andalsvik, 2016). The impact of the disturbances on the network RTK and Precise Point Positioning (PPP) techniques also was studied. The vertical position errors increased rapidly with increasing ROTI for both techniques, but PPP was more precise than RTK at all disturbance levels (Jacobsen and Andalsvik, 2016).

\section{Ionospheric scintillation events in Latvia on 15-21 March 2015}

The aurora borealis caused by geomagnetic storm in St. Patrick's day on 17 March 2015 was observed in wide area in many countries including Latvia (WEB (a), WEB (b)). Global-scale upper atmosphere model parameters reproduce the large-scale general trends in dependence of a few parameters such as the planetary 3-hour-range magnetic index Kp and the geomagnetic index Ap (Namgaladze et al., 2013).

According the geomagnetic storm estimates on 17 March (WEB (c)) the Ap index reached 108 and $\mathrm{Kp}_{\max }=8$ - during time span from 12 till 24 hours of Universal time (Table 1).

Table 1. Geomagnetic storms in St. Patrick's week, March 2015 (WEB (c))

\begin{tabular}{rcrccccccccc}
\hline$\#$ & Date & Ap & $\begin{array}{c}\mathbf{0 0 -} \\
\mathbf{0 3 h}\end{array}$ & $\begin{array}{c}\mathbf{0 3 -} \\
\mathbf{0 6 h}\end{array}$ & $\begin{array}{c}\mathbf{0 6}- \\
\mathbf{0 9 h}\end{array}$ & $\begin{array}{c}\mathbf{0 9 -} \\
\mathbf{1 2 h}\end{array}$ & $\begin{array}{c}\mathbf{1 2 -} \\
\mathbf{1 5 h}\end{array}$ & $\begin{array}{c}\mathbf{1 5}- \\
\mathbf{1 8 h}\end{array}$ & $\begin{array}{c}\mathbf{2 1}- \\
\mathbf{2 1}\end{array}$ & $\begin{array}{c}\mathbf{2 1 -} \\
\mathbf{0 0 h}\end{array}$ & $\begin{array}{c}\text { Kp } \\
\text { max }\end{array}$ \\
\hline 1 & 2015.03 .17 & $\mathbf{1 0 8}$ & 2 & $5-$ & $6-$ & $5+$ & $8-$ & $8-$ & $7+$ & $8-$ & $8-$ \\
2 & 2015.03 .18 & $\mathbf{4 7}$ & 6 & $5-$ & $4+$ & $4+$ & $5+$ & $5+$ & $5-$ & $5-$ & 6 \\
3 & 2015.03 .19 & $\mathbf{2 6}$ & $4+$ & 4 & $4-$ & 5 & $4+$ & 3 & $2+$ & $4-$ & 5 \\
4 & 2015.03 .22 & $\mathbf{2 4}$ & $2+$ & $3+$ & $6+$ & $5-$ & $3+$ & 1 & 1 & 1 & $6+$ \\
\hline
\end{tabular}

The five-minute resolution GNSS observation PPP results were computed at the GGI in kinematic mode by using the scientific post-processing software for the 30 continuously operating GNSS reference stations (CORS) covering the territory of Latvia. The cases of disturbed coordinate values were searched among computed results of the 
week of 15-21 March. The fixed disturbances in CORS station coordinates are depicted in Table 2.

The first coordinate disturbance was fixed in West part of Latvia (IRBE) and just 1 hour after, at 16:40 UT, the disturbances were fixed is East part as well (MADO, REZ1). Maximum intensity has been reached at 17:40 UT when the disturbances were fixed at 10 stations simultaneously. During the 17-18 March geomagnetic storm in Latvia, the disturbances were fixed only on March $17^{\text {th }}$, not on the March $18^{\text {th }}$.

Table 2. Scintillation sequence at the Latvian CORS stations during 15-21 March

\begin{tabular}{|c|c|c|c|c|c|c|c|c|c|c|c|c|c|c|c|}
\hline \multirow{2}{*}{\begin{tabular}{|l|}
$\#$ \\
1 \\
\end{tabular}} & \multirow{2}{*}{ 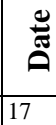 } & \multicolumn{3}{|c|}{$\begin{array}{c}\text { Time interval } \\
\text { UT }\end{array}$} & \multicolumn{11}{|c|}{ Stations } \\
\hline & & $14: 25$ & $15: 15$ & $0: 45$ & IRBE & & & & & & & & & & \\
\hline 2 & 17 & 15:20 & $15: 25$ & $0: 05$ & BAUS & DAU1 & IRBE & & & & & & & & \\
\hline 3 & 17 & $15: 25$ & $15: 30$ & $0: 05$ & IRBE & & & & & & & & & & \\
\hline 4 & 17 & $15: 30$ & $15: 35$ & $0: 05$ & MADO & PREI & REZ1 & IRBE & LODE & & & & & & \\
\hline 5 & 17 & $15: 35$ & 16:00 & $0: 25$ & PREI & REZ1 & IRBE & & & & & & & & \\
\hline 6 & 17 & 16:00 & 16:05 & $0: 05$ & PREI & REZ1 & & & & & & & & & \\
\hline 7 & 17 & $16: 05$ & $16: 10$ & $0: 05$ & PREI & REZ1 & VAL1 & & & & & & & & \\
\hline 8 & 17 & 16:10 & $16: 15$ & $0: 05$ & PREI & REZ1 & & & & & & & & & \\
\hline 9 & 17 & $16: 15$ & $16: 20$ & $0: 05$ & JEK1 & PREI & REZ1 & & & & & & & & \\
\hline 10 & 17 & $16: 20$ & $16: 25$ & $0: 05$ & PREI & REZ1 & IRBE & & & & & & & & \\
\hline 11 & 17 & $16: 25$ & $16: 30$ & $0: 05$ & JEK1 & LIPJ & PREI & REZ1 & & & & & & & \\
\hline 12 & 17 & $16: 30$ & $16: 35$ & $0: 05$ & BAUS & JEK1 & LIPJ & PREI & REZ1 & & & & & & \\
\hline 13 & 17 & $16: 35$ & $16: 40$ & $0: 05$ & DOB1 & JEK1 & LIPJ & REZ1 & & & & & & & \\
\hline 14 & 17 & 16:40 & $16: 45$ & 0:05 & BAUS & JEK1 & LIPJ & MADO & REZ1 & SIGU & IRBE & & & & \\
\hline 15 & 17 & $16: 45$ & $16: 50$ & $0: 05$ & DOB1 & JEK1 & LIPJ & PREI & REZ1 & IRBE & & & & & \\
\hline 16 & 17 & $16: 50$ & $16: 55$ & $0: 05$ & DOB1 & LIPJ & LIMB & PREI & REZ1 & VAL1 & & & & & \\
\hline 17 & 17 & $16: 55$ & 17:00 & $0: 05$ & LIPJ & PREI & REZ1 & VAL1 & & & & & & & \\
\hline 18 & 17 & 17:00 & $17: 05$ & $0: 05$ & JEK1 & LIMB & PREI & REZ1 & VAL1 & & & & & & \\
\hline 19 & 17 & 17:05 & $17: 15$ & $0: 10$ & PREI & REZ1 & VAL1 & & & & & & & & \\
\hline 20 & 17 & $17: 15$ & $17: 20$ & $0: 05$ & LIPJ & PREI & REZ1 & VAL1 & IRBE & & & & & & \\
\hline 21 & 17 & $17: 20$ & $17: 35$ & $0: 15$ & LIPJ & PREI & REZ1 & & & & & & & & \\
\hline 22 & 17 & $17: 35$ & $17: 40$ & $0: 05$ & LIPJ & PREI & REZ1 & \begin{tabular}{|l|} 
VAL1 \\
\end{tabular} & & & & & & & \\
\hline 23 & 17 & $17: 40$ & $17: 45$ & $0: 05$ & ALUK & KUL1 & LIPJ & MADO & OJAR & PREI & REZ1 & TALS & TKMS & LODE & PLSM \\
\hline 24 & 17 & $17: 45$ & $17: 50$ & $0: 05$ & LIPJ & PREI & REZ1 & TALS & TKMS & LODE & & & & & \\
\hline 25 & 17 & $17: 50$ & $17: 55$ & $0: 05$ & LIPJ & PREI & REZ1 & TALS & TKMS & LODE & & & & & \\
\hline 26 & 17 & $17: 55$ & 18:00 & $0: 05$ & PREI & REZ1 & TALS & TKMS & LODE & & & & & & \\
\hline 27 & 17 & 18:00 & 18:05 & $0: 05$ & LIMB & PREI & & & & & & & & & \\
\hline 28 & 17 & 18:05 & $18: 10$ & $0: 05$ & PREI & REZ1 & & & & & & & & & \\
\hline 29 & 17 & 18:10 & $18: 15$ & $0: 05$ & PREI & VAL1 & & & & & & & & & \\
\hline 30 & 17 & 18:15 & 18:20 & $0: 05$ & PREI & & & & & & & & & & \\
\hline 31 & 17 & $18: 20$ & $18: 25$ & $0: 05$ & PREI & & & & & & & & & & \\
\hline 32 & 17 & $23: 05$ & $23: 10$ & $0: 05$ & LIMB & PREI & REZ1 & & & & & & & & \\
\hline 33 & 17 & $23: 15$ & $23: 20$ & $0: 05$ & TALS & & & & & & & & & & \\
\hline 34 & 21 & $23: 25$ & $23: 30$ & $0: 05$ & LIMB & MADO & MAZS & LODE & & & & & & & \\
\hline
\end{tabular}

The most affected stations among 30 five-minute solutions were PREI and REZ1 stations situated in Preili and Rezekne cities, correspondingly (Figure 2). IRBE (near Ventspils) and LIPJ (Liepaja) are most affected stations in Western part of Latvia. EUPOS $^{\circledR}$-Riga stations (KREI, LUNI, SALP, VAIV, VANG) were not affected. 


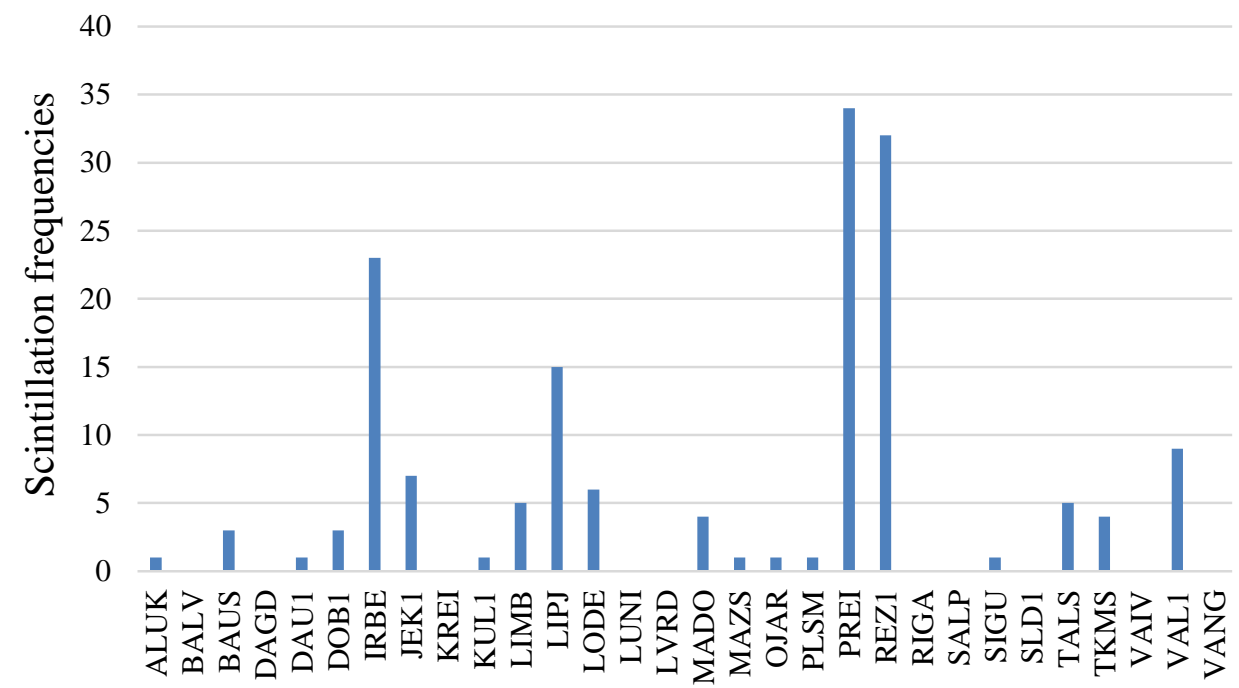

Stations

Fig.2. Scintillation frequencies during 15-21 March 2015

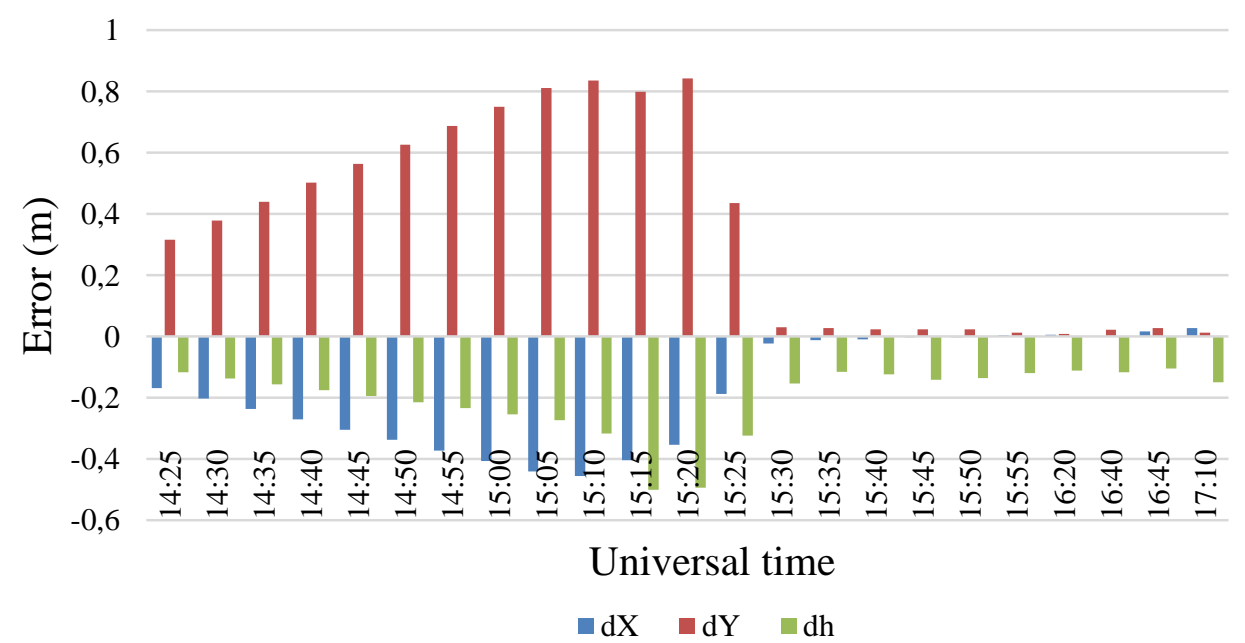

Fig.3. IRBE coordinate errors in five-minute solutions during 17 March 14:25-17:10 UT 
In plot of Figure 3 the disturbed coordinate errors are shown for IRBE station Northing (dX), Easting (dY) and Up (dh) coordinate components. The most affected is Easting component, error reaches up to $0.8 \mathrm{~m}$ on 15:20 UT.

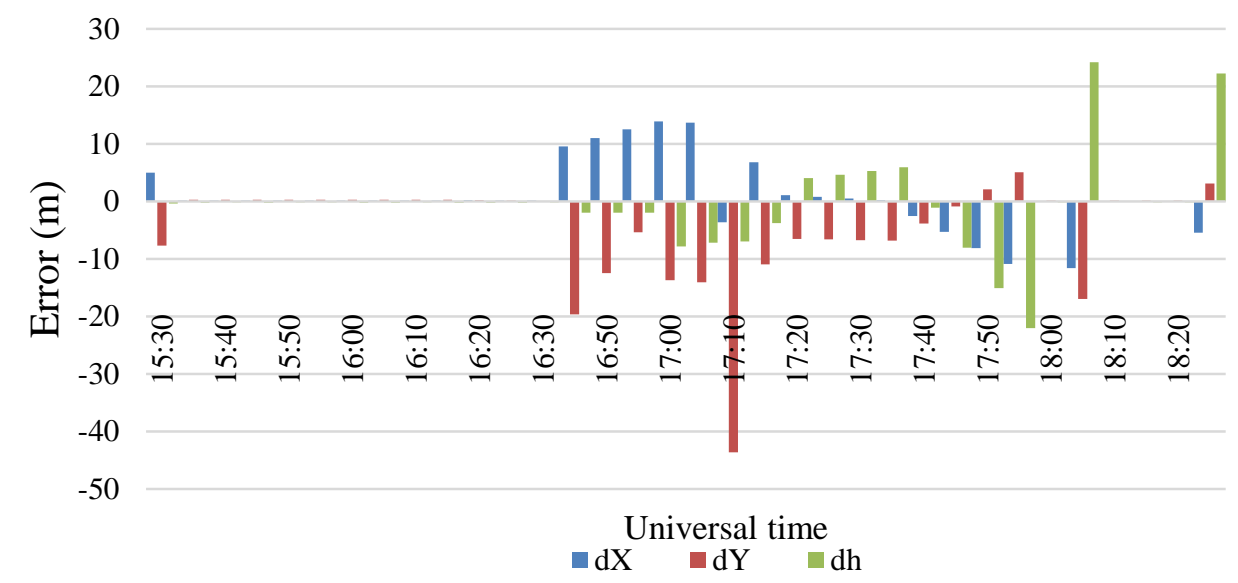

Fig.4. PREI coordinate errors in five-minute solutions during 17 March 15:30-18:20 UT

In plot of Figure 4 the errors are shown for PREI station. The maximum error in Northing component is $14 \mathrm{~m}$ on 17:00 UT, Easting component error is $-43 \mathrm{~m}$ on 17:10 UT and Up component error is $25 \mathrm{~m}$ on 17:10 UT.

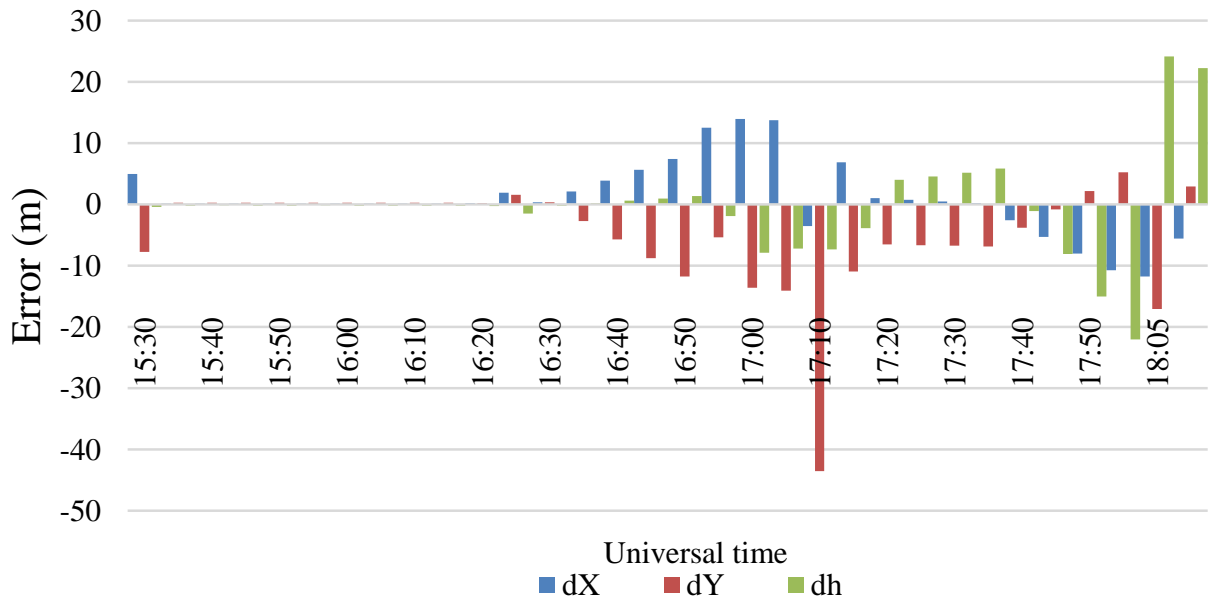

Fig.5. REZ1 coordinate errors in five-minute solutions during 17 March 15:30-18:10 TU 
The REZ1 station (Figure 5) has similar size of errors and similar pattern of error distribution and even the time of maximum errors comparing to PREI (Figure 4).

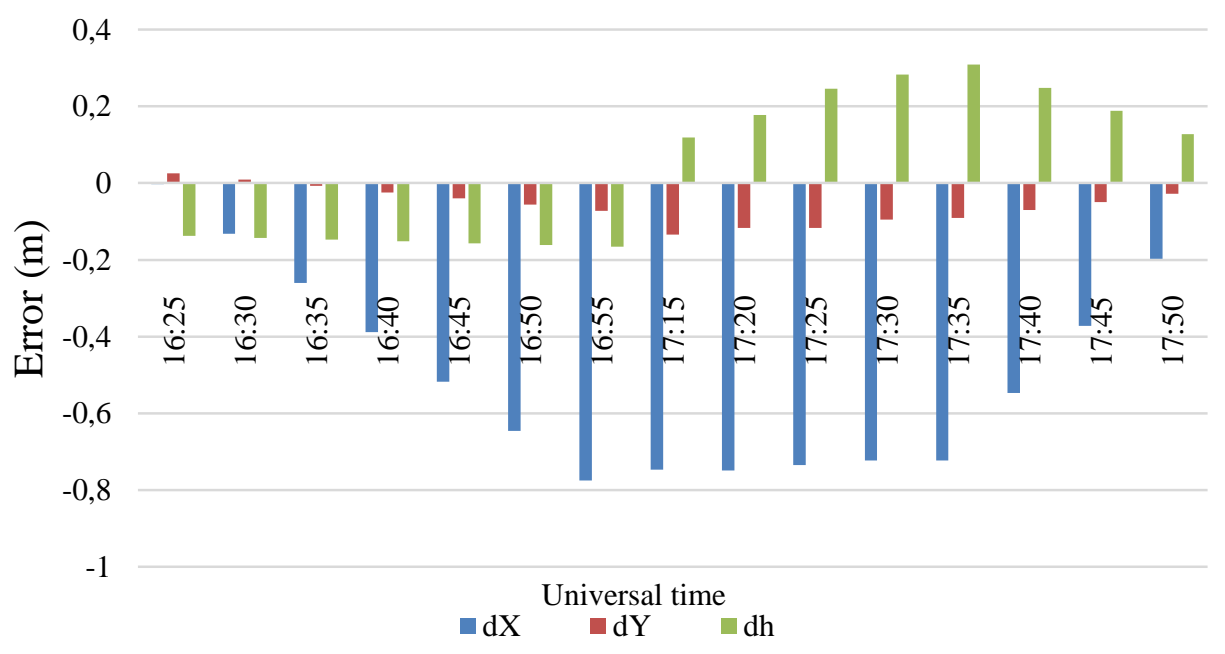

Fig.6. LIPJ coordinate errors in five-minute solutions during 17 March 16:25-17:50 TU

However, the LIPJ (Figure 6) error distribution pattern, size and time are quite different comparing with other Western station IRBE (Figure 3). Interestingly, the error values in Western stations doesn't reach 1 metre against 30-40 m in Eastern part in spite of the fact that they are belonging to the same LatPos network with the same type of GNSS sensors.

\section{The plasma bubble in thermosphere neutral densities derived from Swarm accelerometer and GNSS data}

Zaharenkova (Zaharenkova et al., 2016) confirms that LEO GNSS (Swarm, GRACE, TerraSAR-X ) data can be used as an effective tool for monitoring the occurrence of the topside ionospheric irregularities and may essentially contribute to the multiinstrumental analysis of the ground-based and in situ data. According to the information at the Living Planet Symposium 2016 the various disturbance signals were found in the accelerometer data provided by the Swarm satellites. (Doombos et al., 2016). Swarm C accelerometer along-track axis thermosphere density data has been accomplished, with the help of information about the satellite motion from the GNSS tracking as well as on the attitude from the star trackers. On 22 June 2015 the plasma bubble in thermosphere neutral densities was derived from Swarm accelerometer and GNSS data (Doombos et al., 2016).

Indeed, according the data in Table 3 the geomagnetic storms on 22 and 23 June were quite strong. The event of plasma bubble motivated the researchers in GGI to perform 259200 solutions and to search the scintillation effects in obtained solutions. 
Table 3. Geomagnetic storms in June 2015 (WEB (c))

\begin{tabular}{cccccccccccc}
\hline$\#$ & Date & Ap & $\begin{array}{c}\mathbf{0 0 -} \\
\mathbf{0 3 h}\end{array}$ & $\begin{array}{c}\mathbf{0 3 -} \\
\mathbf{0 6 h}\end{array}$ & $\begin{array}{c}\mathbf{0 6 -} \\
\mathbf{0 9 h}\end{array}$ & $\begin{array}{c}\mathbf{0 9 -} \\
\mathbf{1 2 h}\end{array}$ & $\begin{array}{c}\mathbf{1 2 -} \\
\mathbf{1 5 h}\end{array}$ & $\begin{array}{c}\mathbf{1 5 -} \\
\mathbf{1 8 h}\end{array}$ & $\begin{array}{c}\mathbf{1 8}- \\
\mathbf{2 1 h}\end{array}$ & $\begin{array}{c}\mathbf{2 1 -} \\
\mathbf{0 0 h}\end{array}$ & $\begin{array}{c}\text { Kp } \\
\text { max }\end{array}$ \\
\hline 1 & 2015.06 .08 & $\mathbf{3 6}$ & 3 & $4-$ & 6 & 5 & $4+$ & 5 & $4-$ & $4-$ & 6 \\
2 & 2015.06 .22 & $\mathbf{5 7}$ & 1 & $3+$ & $4+$ & 3 & $5-$ & $5+$ & $8+$ & $5+$ & $8+$ \\
3 & 2015.06 .23 & $\mathbf{7 2}$ & 7 & $8-$ & $6+$ & $5+$ & $6-$ & $3-$ & $4-$ & $3+$ & $8-$ \\
4 & 2015.06 .25 & $\mathbf{3 2}$ & 2 & $3-$ & $5+$ & 5 & $6-$ & $4+$ & $3+$ & $3-$ & $6-$ \\
\hline
\end{tabular}

In resulting five-minute GNSS solutions scintillation events were identified, they are exposed in Table 4. The SALP station appears to be the most affected in June.

Table 4. Scintillation sequence at the CORS stations in June 2015

\begin{tabular}{|c|c|c|c|c|c|c|c|}
\hline \# & Date & \multicolumn{3}{|c|}{ Time interval UT } & \multicolumn{3}{|c|}{ Stations } \\
\hline 1 & 1 & $12: 20$ & $12: 40$ & $0: 20$ & SALP & & \\
\hline 2 & 2 & $9: 50$ & $13: 05$ & $3: 15$ & SALP & & \\
\hline 3 & 2 & 13:05 & $18: 40$ & $5: 35$ & SALP & & \\
\hline 4 & 2 & $23: 35$ & $0: 00$ & $0: 25$ & SALP & & \\
\hline 5 & 3 & $10: 30$ & $10: 40$ & $0: 10$ & MADO & LODE & \\
\hline 6 & 3 & $11: 30$ & $11: 35$ & $0: 05$ & MADO & LODE & \\
\hline 7 & 5 & $3: 25$ & $3: 30$ & $0: 05$ & PREI & REZ1 & \\
\hline 8 & 6 & $21: 05$ & $21: 10$ & $0: 05$ & MADO & LODE & \\
\hline 9 & 7 & $20: 45$ & $20: 50$ & $0: 05$ & MADO & LODE & \\
\hline 10 & 10 & $9: 10$ & $9: 15$ & $0: 05$ & LIPJ & & \\
\hline 11 & 11 & $3: 05$ & $3: 10$ & $0: 05$ & IRBE & & \\
\hline 12 & 11 & $9: 55$ & $10: 05$ & $0: 10$ & MADO & LODE & \\
\hline 13 & 12 & $8: 00$ & $8: 05$ & $0: 05$ & MADO & LODE & \\
\hline 14 & 13 & $21: 45$ & $21: 50$ & $0: 05$ & MADO & LODE & \\
\hline 15 & 17 & $9: 40$ & $9: 45$ & $0: 05$ & TALS & TKMS & \\
\hline 16 & 18 & $13: 35$ & $13: 40$ & $0: 05$ & LIPJ & & \\
\hline 17 & 19 & $9: 25$ & $9: 30$ & $0: 05$ & MADO & LODE & \\
\hline 18 & 19 & $9: 55$ & $10: 00$ & $0: 05$ & MADO & $\begin{array}{l}\text { LODE } \\
\end{array}$ & \\
\hline 19 & 19 & $10: 25$ & $10: 30$ & $0: 05$ & MADO & LODE & \\
\hline 20 & 20 & $11: 15$ & $11: 25$ & $0: 10$ & SALP & & \\
\hline 21 & 20 & $11: 20$ & $11: 25$ & $0: 05$ & SALP & & \\
\hline 22 & 20 & $16: 40$ & $16: 45$ & $0: 05$ & MADO & LODE & \\
\hline 23 & 20 & $21: 40$ & $21: 55$ & $0: 15$ & MADO & LODE & \\
\hline 24 & 20 & $22: 45$ & $22: 55$ & $0: 10$ & SALP & & \\
\hline 25 & 21 & $0: 10$ & $2: 05$ & $1: 55$ & SALP & & \\
\hline 26 & 21 & $3: 45$ & $12: 15$ & $8: 30$ & SALP & & \\
\hline 27 & 21 & $12: 15$ & $12: 20$ & $0: 05$ & SALP & MADO & LODE \\
\hline 28 & 21 & $12: 20$ & 13:00 & $0: 40$ & SALP & & \\
\hline 29 & 21 & $20: 45$ & $20: 50$ & $0: 05$ & MADO & LODE & \\
\hline 30 & 22 & $9: 20$ & $9: 50$ & $0: 30$ & SALP & & \\
\hline 31 & 22 & $9: 50$ & $14: 35$ & $4: 45$ & SALP & MADO & LODE \\
\hline 32 & 22 & $17: 35$ & $17: 40$ & $0: 05$ & MADO & LODE & \\
\hline 33 & 22 & $18: 00$ & 18:05 & 0:05 & LIMB & & \\
\hline 34 & 22 & 19:45 & $19: 50$ & $0: 05$ & LIMB & & \\
\hline 35 & 22 & $\begin{array}{l}19: 50 \\
\end{array}$ & $19: 55$ & $0: 05$ & MAZS & & \\
\hline 36 & 22 & $19: 55$ & $20: 05$ & $0: 10$ & MAZS & & \\
\hline 37 & 22 & $20: 25$ & $20: 30$ & 0:05 & VAL1 & & \\
\hline
\end{tabular}




\begin{tabular}{|l|c|c|c|c|c|c|c|}
\hline 38 & 23 & $6: 50$ & $6: 55$ & $0: 05$ & MADO & LODE & \\
\hline 39 & 23 & $15: 20$ & $15: 25$ & $0: 05$ & MADO & LODE & \\
\hline 40 & 23 & $17: 55$ & $18: 05$ & $0: 10$ & PREI & & \\
\hline 41 & 23 & $18: 25$ & $18: 30$ & $0: 05$ & MADO & LODE & \\
\hline 42 & 24 & $6: 05$ & $6: 10$ & $0: 05$ & LIMB & & \\
\hline
\end{tabular}

Additionally, the other peculiarity appears that a relatively close stations LODE and MADO were disturbed repeatedly most of times comparing with other stations (Figure 7 ). At the each time event the disturbed coordinate value discrepancies (errors) are equal in both stations. In plot of Figure 8 the discrepancies (errors) are depicted for both stations in the period of 20-23 June.

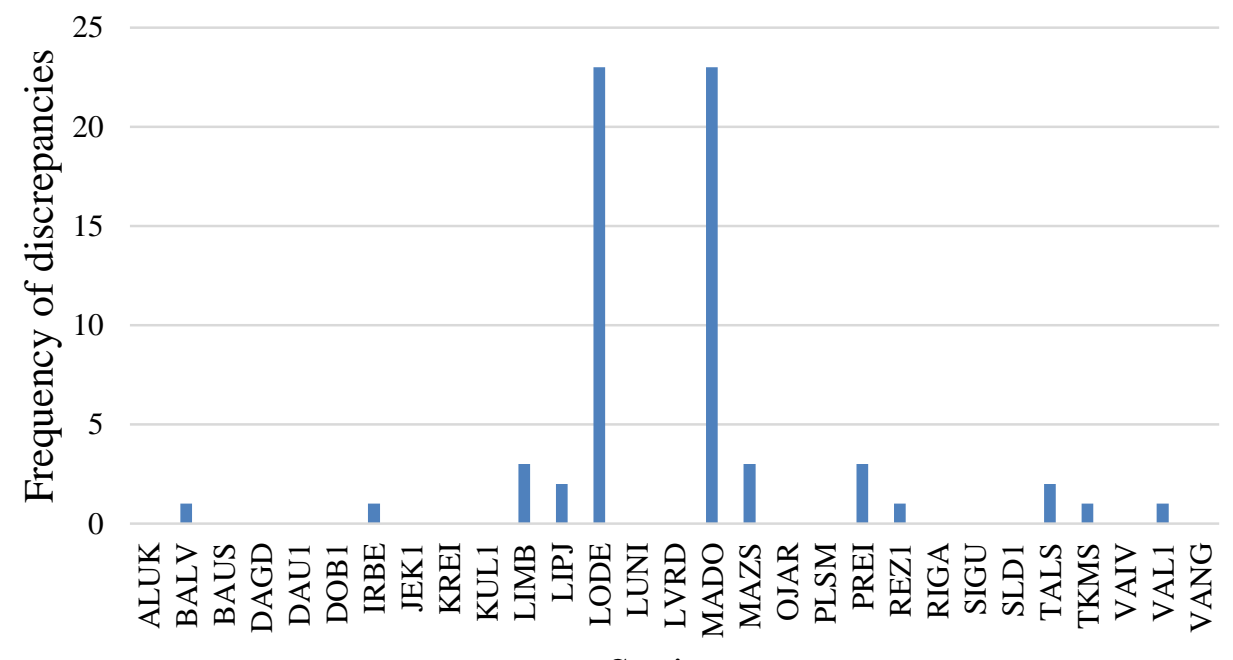

Stations

Fig.7. Frequency of discrepancies of all of the stations (except of SALP) in June 2015

In June 284 SALP five-minute solutions appears disturbed. Among them on 2 June 109 disturbed solutions, 21 June - 106 and 22 June - 61 solution. In plots of Figures 911 the values of discrepancies and the nature of coordinate values disposition on the 2 June, 21 and 22 June are depicted, correspondingly. 


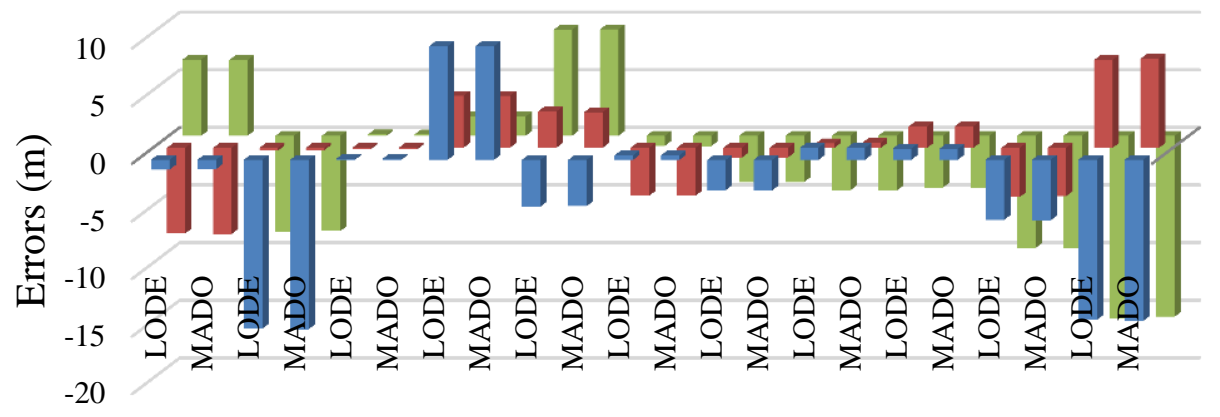

Stations

$\square \mathrm{dX} \backsim \mathrm{dY} \backsim \mathrm{dh}$

Fig.8. LODE and MADO values of discrepancies during 20-23 June 2015

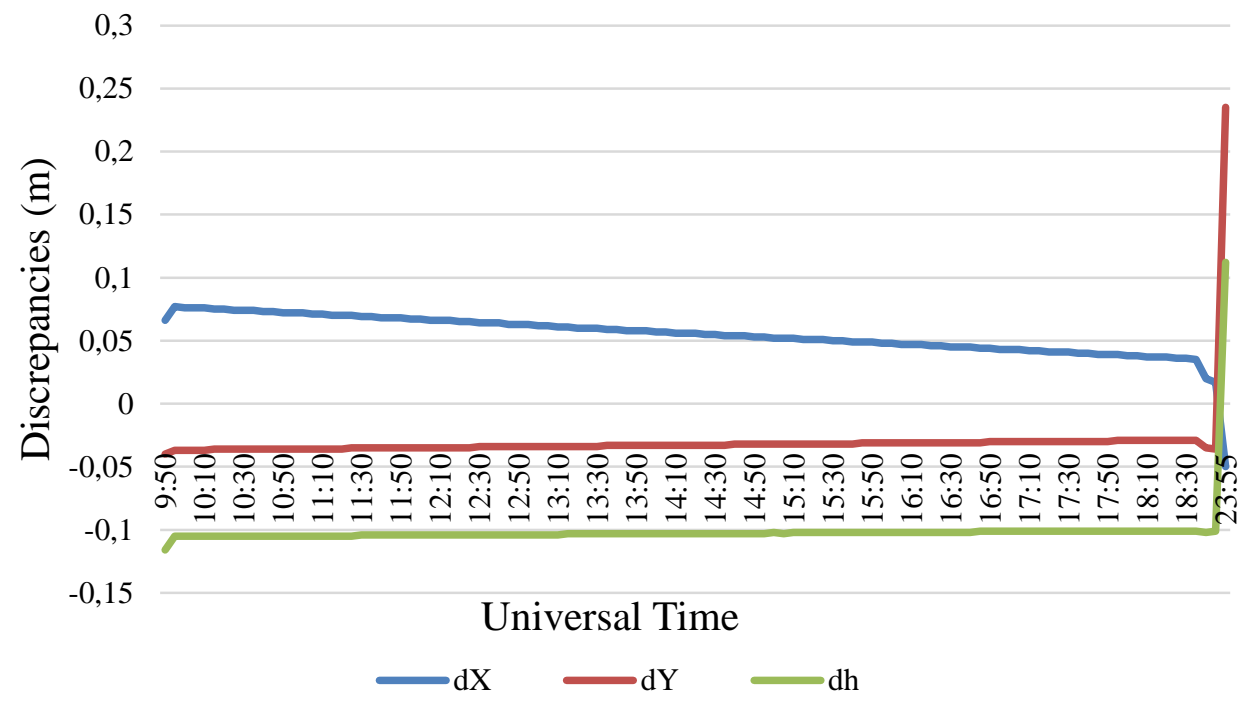

Fig.9. SALP coordinate discrepancies (m) on 2 June 2015 


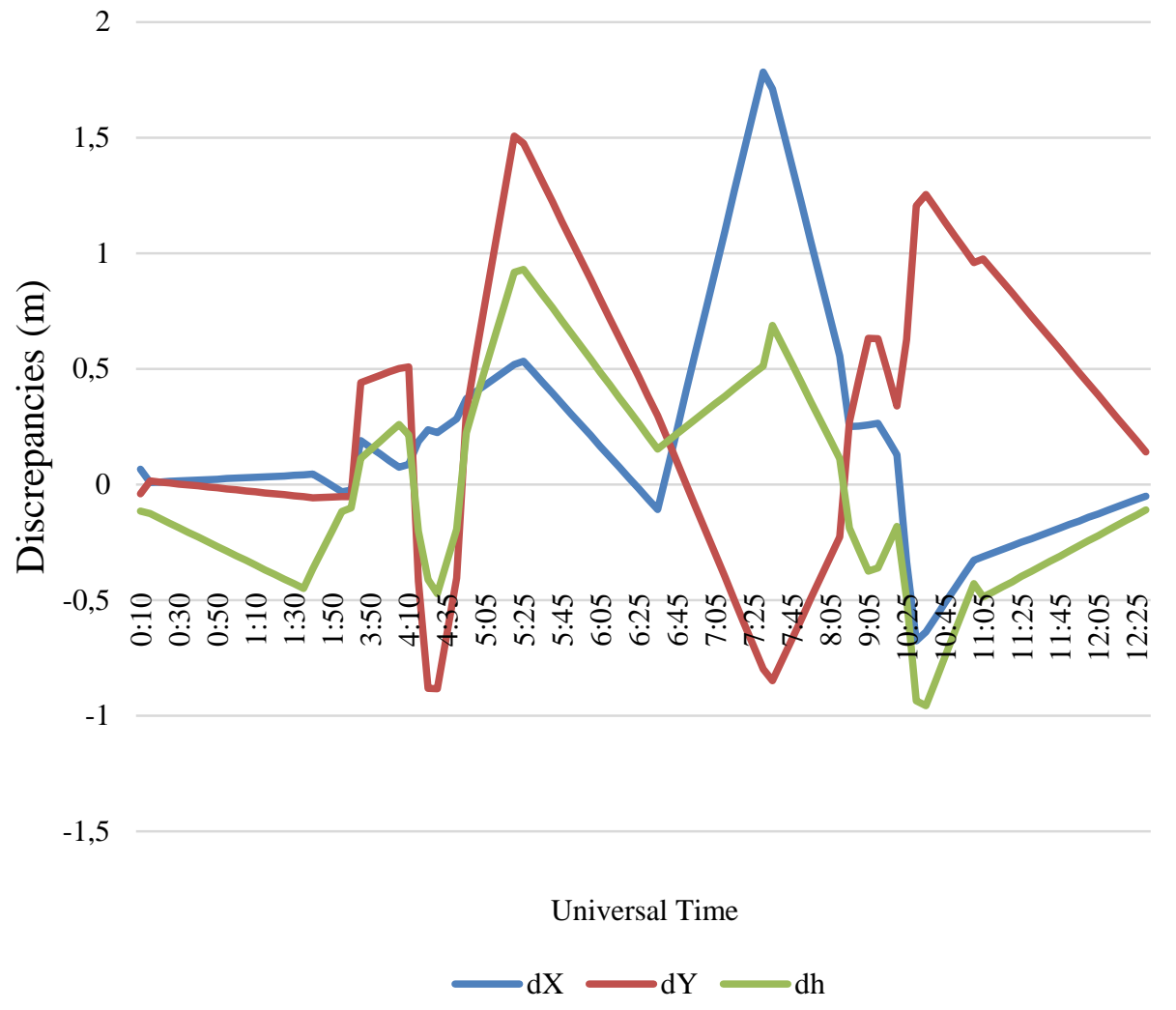

Fig.10. SALP coordinate discrepancies (m) on 21 June 2015

The SALP discrepancies are comparatively small on the 2 June (Figure 9) but they are unchanged for more than 8 hours. On the 21 June (Figure 10) the disturbances are very chaotic in time span of 12 hours. On the 22 June (Figure 11) the most affected is Up component. 


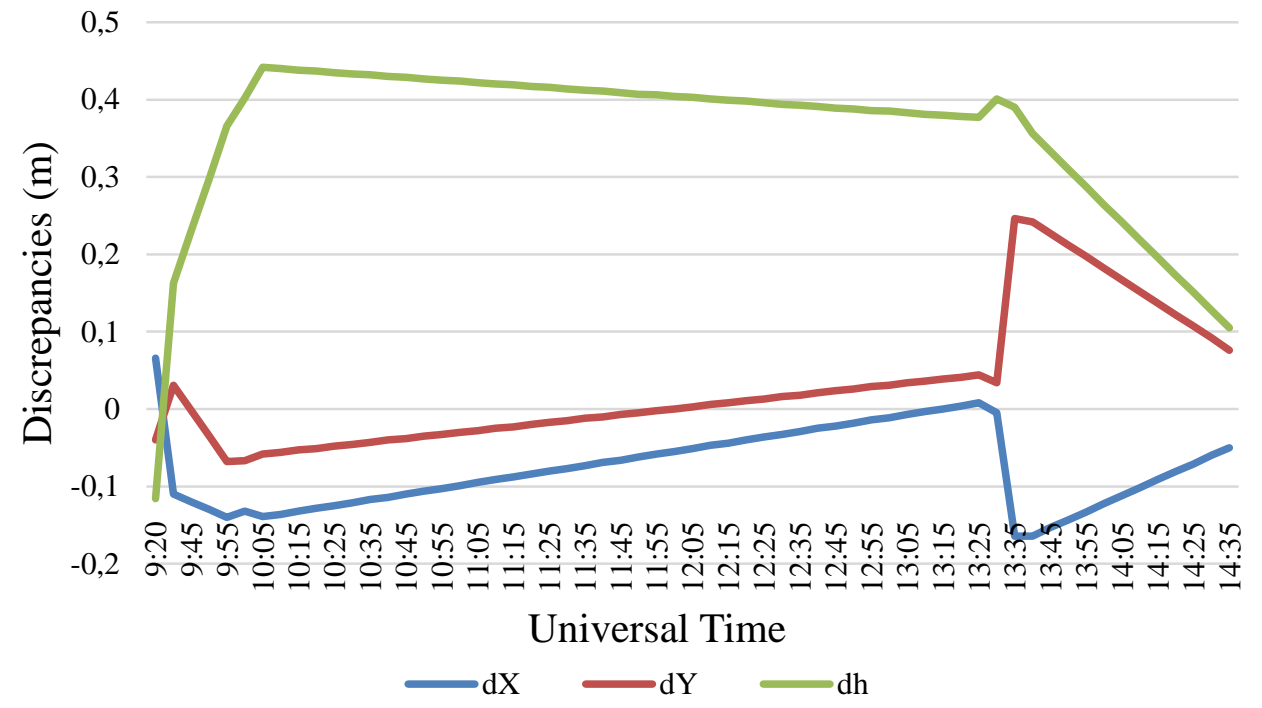

Fig.11. SALP coordinate discrepancies (m) on 22 June 2015

In conclusion, talking about the plasma bubble of 22 June, the CORS stations in Latvia were affected just in small region before the time when geomagnetic storm achieved the maximum strength (Table 3).

\section{Scintillation effects in September 2015}

In presentation at the Living Planet Symposium 2016 (Doombos et al., 2016) it was noticed that the accelerometer data provided by the Swarm satellites did not recognized any proper plasma bubbles in September 2015. So, it was a quiet period, contra verse to periods analyzed above. In the Table 5 it is shown that, however, geomagnetic storms with $\mathrm{Kp}>5+$ happened 5 times during this month.

Table 5. Geomagnetic storms in September 2015 (WEB (c))

\begin{tabular}{cccccccccccc}
\hline$\#$ & Date & Ap & $\begin{array}{c}\mathbf{0 0 -} \\
\mathbf{0 3 h}\end{array}$ & $\begin{array}{c}\mathbf{0 3 -} \\
\mathbf{0 6 h}\end{array}$ & $\begin{array}{c}\mathbf{0 6 -} \\
\mathbf{0 9 h}\end{array}$ & $\begin{array}{c}\mathbf{0 9 -} \\
\mathbf{1 2 h}\end{array}$ & $\begin{array}{c}\mathbf{1 2 -} \\
\mathbf{1 5 h}\end{array}$ & $\begin{array}{c}\mathbf{1 5 -} \\
\mathbf{1 8 h}\end{array}$ & $\begin{array}{c}\mathbf{1 8 -} \\
\mathbf{2 1 h}\end{array}$ & $\begin{array}{c}\mathbf{2 1 -} \\
\mathbf{0 0 h}\end{array}$ & $\begin{array}{c}\text { Kp } \\
\text { max }\end{array}$ \\
\hline 1 & 07.09 .2015 & $\mathbf{4 4}$ & $2+$ & 3 & $4-$ & $3-$ & $5-$ & $6+$ & $6-$ & $6+$ & $6+$ \\
2 & 08.09 .2015 & $\mathbf{2 4}$ & 6 & $5+$ & $3-$ & $1+$ & 2 & 2 & $2-$ & $4-$ & 6 \\
3 & 09.09 .2015 & $\mathbf{5 9}$ & 4 & $6-$ & 6 & 6 & $5+$ & $5-$ & $6-$ & $5+$ & 6 \\
4 & 11.09 .2015 & $\mathbf{6 0}$ & 3 & 4 & 7 & $6+$ & $6-$ & $7-$ & 3 & $4-$ & 7 \\
5 & 20.09 .2015 & $\mathbf{4 4}$ & 3 & $5-$ & 7 & $5+$ & $4+$ & 5 & $3-$ & 3 & 7 \\
\hline
\end{tabular}

For comparison, the kinematic five-minute resolution solutions were performed in GGI for all the above mentioned stations for period 1-30 September 2015. The coordinate disturbances appear even more (Figure 12) than during 5 days (Table 6). Actually, Leick (2004) point out that even a quiet sun emits radio energy across a broad frequency spectrum, with slow varying intensity. In Table 6 the scintillation sequence 
was recorded. In various cases the scintillation occurred in several stations simultaneously similarly like it was in the periods analyzed above.

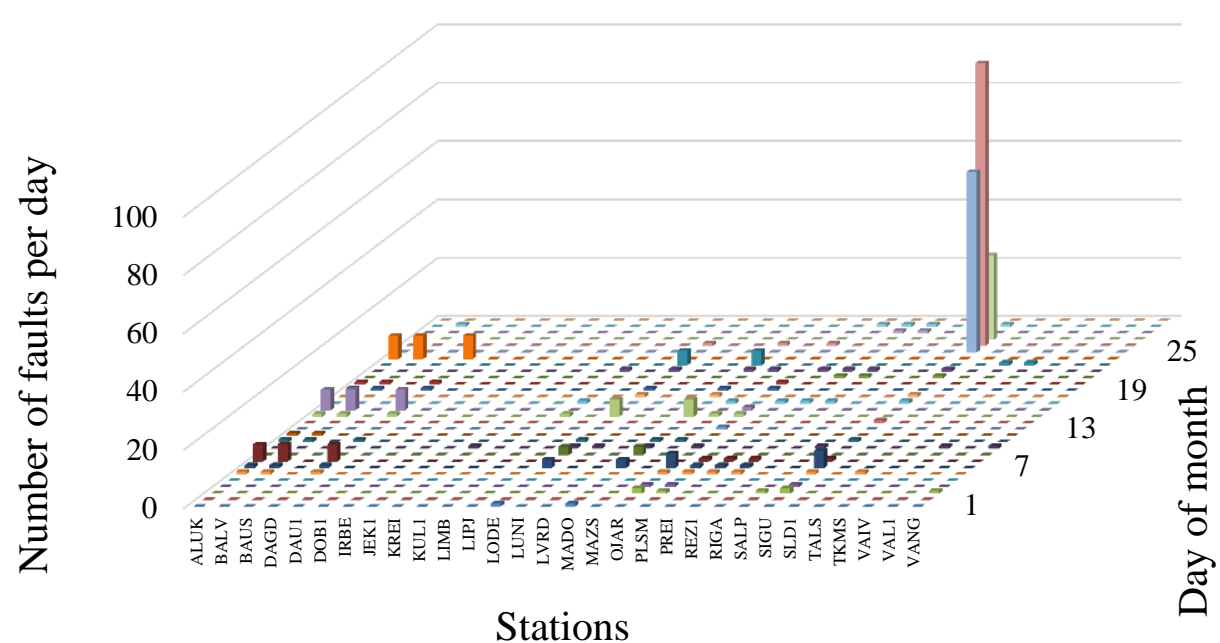

Fig.12. Frequencies of solution discrepancies in September 2015

In plot of Figure 12 is shown that most disturbed is the SIGU station with a long duration of disturbances in 25-27 September. LODE, MADO are simultaneously affected in 22 solutions, 3 stations ALUK, BALV, DAGD are simultaneously affected in 22 solutions. OJAR is affected 11 times, LODE - 10, PLSM, REZ1 are affected 7 times but other LatPos stations are affected 6 times and less for no long duration. All EUPOS $^{\circledR}$-Riga stations are affected simultaneously once on 10 September 2015.

Table 6. Scintillation sequence at the CORS stations in September 2015

\begin{tabular}{|c|c|c|c|c|c|c|c|l|l|}
\hline$\#$ & Date & \multicolumn{3}{|c|}{ Time interval UT } & \multicolumn{5}{c|}{ Stations } \\
\hline 1 & 1 & $16: 15$ & $16: 20$ & $0: 05$ & MADO & LODE & & & \\
\hline 2 & 1 & $21: 10$ & $21: 15$ & $0: 05$ & DAU1 & & & & \\
\hline 3 & 3 & $10: 30$ & $10: 40$ & $0: 10$ & OJAR & SIGU & PLSM & & \\
\hline 4 & 3 & $13: 15$ & $13: 20$ & $0: 05$ & OJAR & & & & \\
\hline 5 & 3 & $13: 25$ & $13: 30$ & $0: 05$ & OJAR & SIGU & & & \\
\hline 6 & 3 & $15: 00$ & $15: 05$ & $0: 05$ & SALP & VANG & & & \\
\hline 7 & 4 & $14: 25$ & $14: 30$ & $0: 05$ & OJAR & SIGU & PLSM & & \\
\hline 8 & 6 & $7: 30$ & $7: 40$ & $0: 10$ & TALS & & & & \\
\hline 9 & 6 & $7: 50$ & $7: 55$ & $0: 05$ & OJAR & PREI & REZ1 & SIGU & PLSM \\
\hline 10 & 6 & $17: 10$ & $17: 15$ & $0: 05$ & ALUK & BALV & DAGD & & \\
\hline 11 & 7 & $0: 40$ & $0: 45$ & $0: 05$ & ALUK & BALV & DAGD & & \\
\hline 12 & 7 & $4: 40$ & $4: 55$ & $0: 15$ & MADO & LODE & & & \\
\hline 13 & 7 & $4: 55$ & $5: 00$ & $0: 05$ & OJAR & PREI & & & \\
\hline 14 & 7 & $14: 05$ & $14: 30$ & $0: 25$ & OJAR & SIGU & & & \\
\hline 15 & 8 & $2: 50$ & $3: 50$ & $1: 00$ & ALUK & BALV & DAGD & & \\
\hline 16 & 8 & $15: 40$ & $15: 45$ & $0: 05$ & ALUK & BALV & DAGD & & \\
\hline 17 & 8 & $21: 30$ & $21: 35$ & $0: 05$ & PREI & REZ1 & SIGU & PLSM & \\
\hline 18 & 9 & $15: 50$ & $16: 05$ & $0: 15$ & MADO & LODE & & & \\
\hline 19 & 10 & $13: 00$ & $13: 05$ & $0: 05$ & OJAR & & & & \\
\hline
\end{tabular}




\begin{tabular}{|c|c|c|c|c|c|c|c|c|c|}
\hline 20 & 10 & $14: 45$ & $14: 50$ & 0:05 & MADO & LODE & & & \\
\hline 21 & 10 & 16:00 & $16: 05$ & $0: 05$ & SALP & KREI & LUNI & VAIV & VANG \\
\hline 22 & 11 & $12: 55$ & 13:00 & $0: 05$ & ALUK & BALV & DAGD & & \\
\hline 23 & 11 & 13:00 & $13: 05$ & 0:05 & SIGU & & & & \\
\hline 24 & 11 & $18: 10$ & $18: 15$ & $0: 05$ & MADO & MAZS & LODE & & \\
\hline 25 & 12 & $6: 05$ & $6: 10$ & $0: 05$ & ALUK & BALV & & & \\
\hline 26 & 13 & $16: 20$ & $16: 25$ & $0: 05$ & OJAR & & & & \\
\hline 27 & 14 & $16: 20$ & $16: 25$ & $0: 05$ & SIGU & & & & \\
\hline 28 & 15 & $4: 10$ & $4: 35$ & $0: 25$ & MADO & LODE & & & \\
\hline 29 & 15 & $7: 35$ & $7: 40$ & $0: 05$ & LIMB & MAZS & & & \\
\hline 30 & 15 & $15: 25$ & $15: 30$ & 0:05 & OJAR & & & & \\
\hline 31 & 15 & $16: 10$ & $16: 15$ & $0: 05$ & MADO & LODE & & & \\
\hline 32 & 15 & $19: 15$ & $19: 20$ & $0: 05$ & ALUK & BALV & DAGD & & \\
\hline 33 & 16 & 19:00 & 19:05 & 0:05 & OJAR & & & & \\
\hline 34 & 17 & $14: 30$ & $14: 35$ & $0: 05$ & LIMB & MAZS & & & \\
\hline 35 & 17 & $15: 25$ & $15: 30$ & $0: 05$ & PREI & REZ1 & SIGU & PLSM & \\
\hline 36 & 18 & $14: 10$ & $14: 15$ & $0: 05$ & MADO & LODE & & & \\
\hline 37 & 18 & 19:00 & 19:05 & $0: 05$ & SIGU & & & & \\
\hline 38 & 19 & $8: 45$ & $8: 50$ & $0: 05$ & OJAR & & & & \\
\hline 39 & 19 & $9: 55$ & 10:00 & $0: 05$ & ALUK & BALV & DAGD & & \\
\hline 40 & 19 & $12: 30$ & $18: 35$ & $0: 05$ & MADO & LODE & & & \\
\hline 41 & 20 & 10:05 & $10: 10$ & $0: 05$ & ALUK & BALV & DAGD & & \\
\hline 42 & 20 & $21: 10$ & $21: 15$ & $0: 05$ & OJAR & & & & \\
\hline 43 & 21 & $8: 45$ & $8: 50$ & $0: 05$ & PREI & REZ1 & SIGU & & \\
\hline 44 & 22 & $18: 40$ & $18: 45$ & $0: 05$ & LIMB & MADO & MAZS & LODE & \\
\hline 45 & 22 & $21: 10$ & $21: 15$ & $0: 05$ & PREI & REZ1 & SIGU & PLSM & \\
\hline 46 & 23 & $3: 40$ & $4: 05$ & $0: 25$ & MADO & LODE & & & \\
\hline 47 & 23 & $20: 25$ & $20: 30$ & $0: 05$ & TALS & TKMS & & & \\
\hline 48 & 24 & $2: 25$ & $2: 45$ & $0: 20$ & ALUK & BALV & DAGD & & \\
\hline 49 & 24 & $3: 00$ & $3: 05$ & $0: 05$ & ALUK & BALV & DAGD & & \\
\hline 50 & 24 & $14: 25$ & $14: 40$ & $0: 15$ & ALUK & BALV & DAGD & & \\
\hline 51 & 25 & $5: 20$ & $5: 45$ & $0: 25$ & SIGU & & & & \\
\hline 52 & 25 & $5: 45$ & $6: 15$ & $0: 30$ & JEK1 & SIGU & & & \\
\hline 53 & 25 & $6: 15$ & $6: 35$ & $0: 20$ & SIGU & & & & \\
\hline 54 & 25 & 13:05 & $13: 45$ & $0: 40$ & SIGU & & & & \\
\hline 55 & 25 & $13: 45$ & $13: 50$ & $0: 05$ & BALV & SIGU & & & \\
\hline 56 & 25 & $13: 50$ & $15: 50$ & $2: 00$ & SIGU & & & & \\
\hline 57 & 25 & $16: 35$ & $17: 45$ & $1: 10$ & SIGU & & & & \\
\hline 58 & 25 & $18: 20$ & $18: 55$ & $0: 35$ & SIGU & & & & \\
\hline 59 & 25 & 19:30 & $20: 25$ & $0: 55$ & SIGU & & & & \\
\hline 60 & 25 & $21: 25$ & 23:05 & $1: 40$ & SIGU & & & & \\
\hline 61 & 25 & $23: 30$ & $0: 00$ & $0: 30$ & SIGU & & & & \\
\hline 62 & 26 & $0: 05$ & $2: 45$ & $2: 40$ & SIGU & & & & \\
\hline 63 & 26 & $9: 20$ & $10: 30$ & $1: 10$ & SIGU & & & & \\
\hline 64 & 26 & $13: 25$ & $13: 30$ & $0: 05$ & SIGU & & & & \\
\hline 65 & 26 & $13: 30$ & $13: 35$ & $0: 05$ & MADO & SIGU & LODE & & \\
\hline 66 & 26 & $13: 40$ & $13: 45$ & $0: 05$ & SIGU & & & & \\
\hline 67 & 26 & $14: 40$ & $21: 15$ & $6: 35$ & SIGU & & & & \\
\hline 68 & 27 & $3: 25$ & $3: 30$ & 0:05 & SIGU & & & & \\
\hline 69 & 27 & $4: 10$ & $7: 25$ & $3: 15$ & SIGU & & & & \\
\hline 70 & 27 & $8: 25$ & $9: 20$ & $0: 55$ & SIGU & & & & \\
\hline 71 & 27 & $14: 15$ & $14: 35$ & $0: 20$ & SIGU & & & & \\
\hline 72 & 28 & $7: 50$ & $7: 55$ & $0: 05$ & PREI & REZ1 & & & \\
\hline 73 & 29 & $1: 50$ & $1: 55$ & $0: 05$ & SIGU & & & & \\
\hline 74 & 29 & $7: 30$ & $7: 35$ & $0: 05$ & BALV & & & & \\
\hline 75 & 29 & $14: 50$ & $14: 55$ & $0: 05$ & PREI & REZ1 & PLSM & & \\
\hline
\end{tabular}


The behavior of station SIGU is very strange in 25-27 September (Figures 13-15) where Easting component's discrepancies (dY) in some solutions achieve 30 metres. Actually, the source of these discrepancies is not discovered in this article. Leick (2004) describes that there are local disturbances of electron density in the ionosphere. On a small scale irregularities of a few hundred meters in size can cause amplitude fading and phase scintillation of GNSS signals. Larger disturbances of the size of a few kilometres can significantly impact the TEC. Amplitude fading and scintillation can cause receivers to lose lock, or receivers may not be able to maintain lock for prolonged period of time. Scintillation on GNSS frequencies is rare in the mid-altitudes and amplitude scintillation even under geomagnetically disturbed conditions, is normally not large in the auroral regions. However, rapid phase scintillation can be a problem in both the equatorial and auroral regions, especially for semi codeless $\mathrm{L} 2$ receivers as the bandwidth of such receivers might be too narrow to follow rapid phase scintillation effects. (Leick 2004, 213.p).

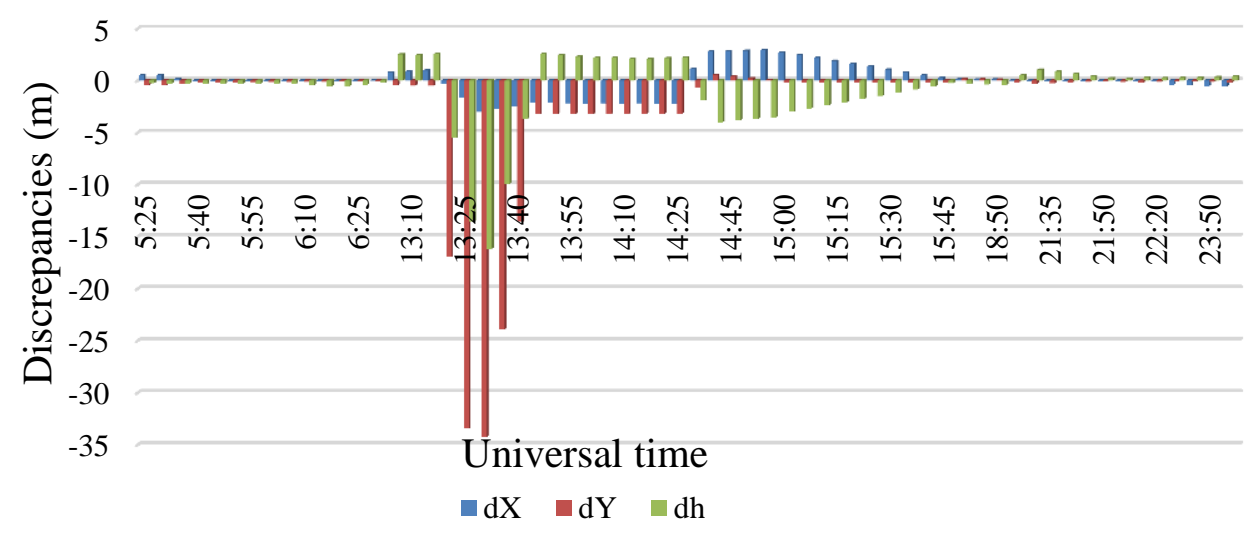

Fig. 13. SIGU coordinate discrepancies (m) 25 September 2015

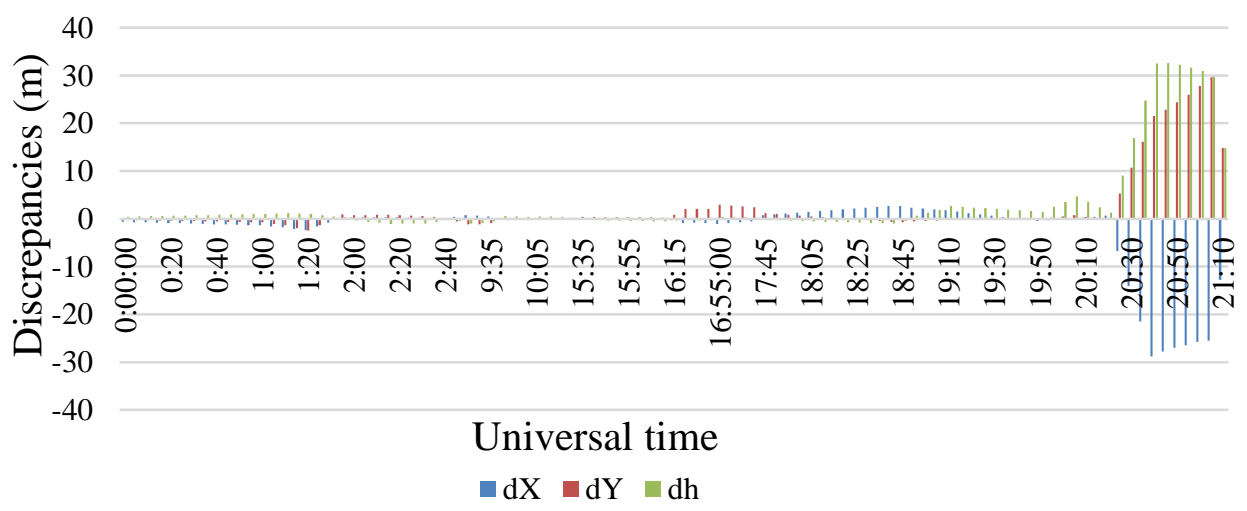

Fig.14. SIGU coordinate discrepancies (m) 26 September 2015 


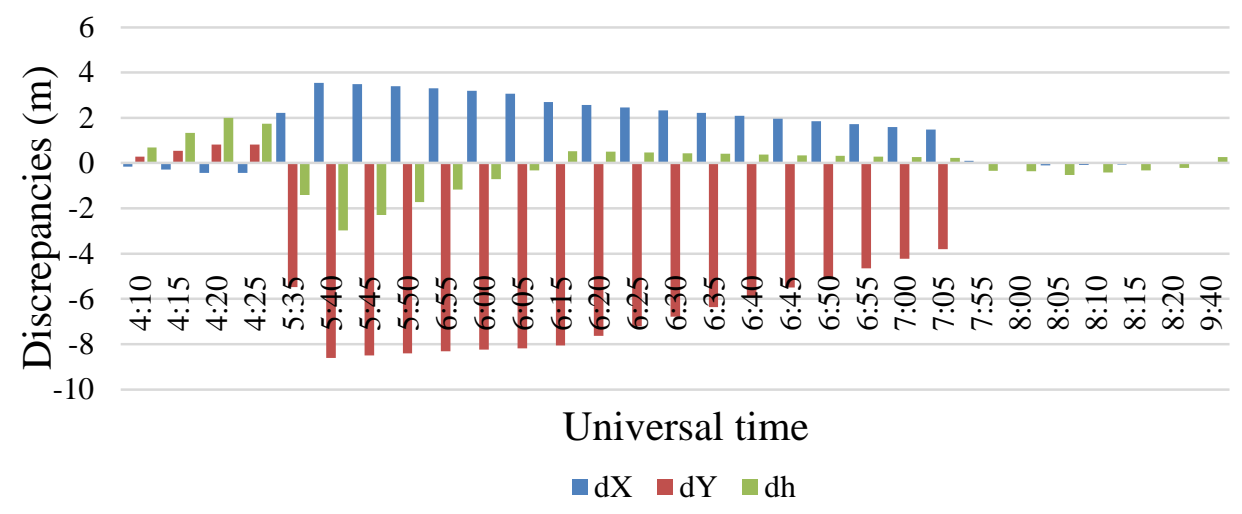

Fig.15. SIGU coordinate discrepancies (m) 27 September 2015

Discrepancy values are usually equal for stations which are affected simultaneously at the same time. For example, in plot of Figure 16 station ALUK, BALV and DAGD coordinate disturbances (errors) are depicted for solutions of GNSS observations on 8 September from 03:30 till 03:45 UT.

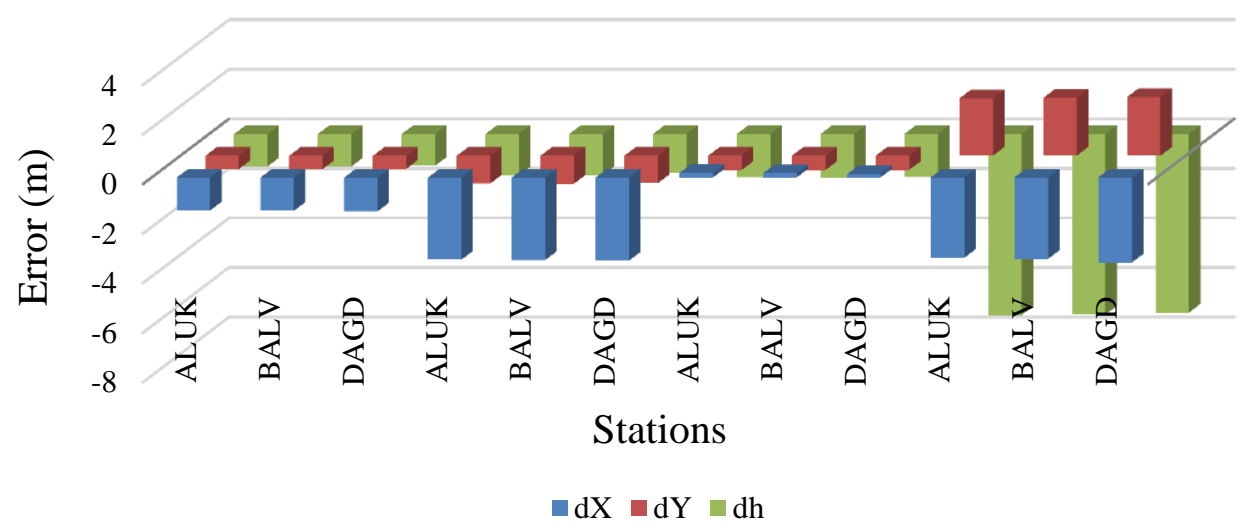

Fig.16. Station ALUK, BALV and DAGD solution 8 September 03:30-03:45 UT coordinate disturbances (errors)

In Table 7 the summarized average, standard deviation, minimum and maximum values of discrepancies in Northing, Easting and Up are depicted. Min/max values have achieved more than \pm 30 metres in both horizontal and vertical components, correspondingly. From all of the 259200 solutions 395 solutions were disturbed in September, i.e. $0.15 \%$ from all solutions. 
Table 7. Discrepancy statistics in September 2015

\begin{tabular}{cccc}
\hline & Northing $(\mathbf{m})$ & Easting $(\mathbf{m})$ & Up $(\mathbf{m})$ \\
\hline Average & -0.827 & -0.427 & -0.319 \\
STDV & 5.474 & 5.302 & 7.191 \\
Min & -28.821 & -34.262 & -34.117 \\
Max & 38.638 & 29.632 & 32.593 \\
\hline
\end{tabular}

\section{Conclusions}

In order to find the scintillation events, the precise point positioning five-minute kinematic solutions were performed at GGI: for March - 60480, June - 259200 and September - 259200 solutions. The standart deviation of space weather non affected solutions is $0.005 \mathrm{~m}$ for Northing, $0.003 \mathrm{~m}$ for Easting and $0.01 \mathrm{~m}$ for Up component.

$\mathrm{Min} / \mathrm{max}$ values for space weather affected solutions have achieved more than \pm 30 metres in both horizontal and vertical components, correspondingly.

Discrepancy values are usually equal for stations which are affected simultaneously at the same time.

In 17 March CORS station disturbances were fixed in Latvia, in spite of the fact, that much higher plasma densities were observed in the Southern Hemisphere than in the Northern Hemisphere.

SALP station was strongly affected in June. In March and September this station was behaving normally.

SIGU station was strongly affected in September. In March and June this station was behaving normally.

In the lists of geomagnetic storms there are not reported the variously affected areas on the Earth, they reflect the global effect only. Actually, the effect of space weather is recorded as different at the same time in different regions. The research results of this paper expose the space weather irregular changes and irregular GNSS positioning disturbances in CORS of Latvia. The five-minute resolution GNSS observation results computed in kinematic mode for the GNSS ground based continuously operating reference stations are representing a reasonable contribution for recognition of space weather anomalies. The space weather anomalies is a reason for GNSS related navigation sudden errors.

\section{Acknowledgements}

The research was developed under the contract No.S193-ESS198F-ZF-N-290. 


\section{References}

Astafyeva, E., Zakharenkova, I., Förster, M. (2015). Ionospheric response to the 2015 St. Patrick's Day storm: A global multi-instrumental overview, In: J. Geophys. Res. Space Physics, 120, 9023-9037, DOI:10.1002/2015JA021629.

Cherniak, I., Zakharenkova, I., Redmon, R.J. (2015). Dynamics of the high-latitude ionospheric irregularities during the 17 March 2015 St. Patrick's Day storm: ground-based GPS measurements, In: Space Weather, 13 (9), 585-597, DOI:10.1002/2015SW001237.

Dach, R., Lutz, S., Walser, P., Fridez, P. (2015). Bernese GNSS Software Version 5.2. Astronomical Institute, University of Bern, Bern, Switzerland. 852 p.

Doornbos, E., Encarnacao, J., Ijssel, J., Siemes, C., Grunwaldt, L., Peresty, R., Kraus, J., Flury, J., Apelbaum, G., Holmdahl, O.P.E. (2016). Thermospheric neutral densities derived from Swarm accelerometer and GPS data, In: ESA Living Planet Symposium, SP-740, (9-13 May 2016, Prague, Czech Republic).

Doornbos, E., Ijssel, J., Luhr, H., Förster, M., Koppenwalner, G. (2010). Neutral density and crosswind determination from arbitrarily oriented multi-axis accelerometers on satellites, In: J.Spacecraft Rockets, 47: 580-589. DOI:10.2514/1.48114.

Goodwin, L., Iserhienrhien, B., Miles, D.M., Patra, S., van der Meeren, C., Buchert, S.C., Burchill, J., Clausen, L.B.N., Knudsen, D.J., McWilliams, K.A., Moen, J. (2015). Swarm in situ observations of $F$ region polar cap patches created by cusp precipitation, In: Res Lett, Geophys, 42 (4), 96-1003, DOI:10.1002/2014GL062610.

Jacobsen, K.S. and Andalsvik, Y.L. (2016). Overview of the 2015 St. Patrick's day storm and its consequences for RTK and PPP positioning in Norway, In: J. Space Weather Space Climate, Volume 6, A9, DOI:10.1051/swsc/2016004.

Jinyun, G., Wang, L., Xin, L., Qiaoli, K., Chunmei, Z., Bin, G. (2015). Temporal-Spatial Variation of Global GPS-Derived Total Electron Content, 1999-2013, In: PLoS One. 10(7): e0133378, DOI:10.1371/journal.pone.0133378.

Leick, A. (2004). GPS satellite surveying. Third edition. John Wiley \& Sons inc.,New Jersey USA and Canada. $425 \mathrm{p}$.

Liu, J., Wang, W., Burns, A., Yue, X., Zhang, S., Zhang, Y., Huang, C. (2015). Profiles of ionospheric storm-enhanced density during the 17 March 2015 great storm, In: J Geophys Res Space Phys, 121:727, DOI:10.1002/2015JA021832.

Namgaladze, A.A., Förster, M., Prokhorov, B.E., Zolotov, O.V. (2013). Electromagnetic drivers in the upper atmosphere: Observations and modelling, In: Bichkov, V., et al. (eds.) The atmosphere and ionosphere, Physics of Earth and Space environment ${ }^{(B)}$, Springer science+Business Media B.V., 166-219, DOI:10.1007/978-94-007-2914-8_4.

Zakharenkova, I., Astafyeva, E., Cherniak, I. (2016). Detection of the ionospheric plasma density irregularities by spaceborne GPS measurements, In: ESA Living Planet Symposium (9-13 May 2016, Prague, Czech Republic).

WEB (a). SpaceWeatherLive.com https://www.spaceweatherlive.com/en/auroral-activity/top-50geomagnetic-storms

WEB (b). http://jauns.lv/raksts/zinas/56804-latvija-novero-pedejo-gadu-spilgtako-ziemelblazmufoto-video

WEB (c). http://www.lsm.lv/raksts/laika-zinas/laika-zinas/foto-un-video-nakti-daudzviet-latvijaun-citur-pasaule-noverota-spilgta-ziemelblazma.a121924/ 